\title{
Las oraciones con se en español y su representación en polaco
}

\section{Sentences with se in Spanish and its Representation in Polish}

\author{
Raúl Fernández Jódar \\ Departament of Romance Studies, Adam Mickiewicz University, \\ Al. Niepodległości 4, 61-874 Poznań, Poland \\ email: raulfdez@amu.edu.pl
}

\begin{abstract}
In this paper we analyze the different syntactic-functional characteristics of $s e$. The form se has different uses in Spanish, which, by their variety and differences with respect to Polish and, since not all of these values are represented in the same way, may be a problem for Polish learners of Spanish as a foreign language. On the one hand, he is a personal unstressed pronoun belonging to the series me, te, se, nos, $o s, s e$, and as such it can function as direct or indirect object. Thus, we have a series of pronouns that vary according to the number and person in Spanish, and they are equivalent to two unique forms in Polish depending on their grammatical function. Furthermore, it can appear in sentences whose main characteristic is to represent processes and states as in the passive or impersonal sentences, and also we have a Polish non-existent structure such as the passive-reflexive sentence. The fact that this structure has no equivalent in Polish motivates some difficulties for Polish learners of Spanish as a foreign language. Moreover, such sentences are often ignored during learning, so that difficulties remain over time.
\end{abstract}

Keywords: pronoun, passive sentence, impersonal sentence, passive-reflexive sentence, Spanish as a foreign language

\section{INTRODUCCIÓN}

La forma se tiene diferentes usos en español, los cuales -por su variedad y diferencias respecto al polaco- pueden suponer un problema, puesto que no todos estos valores se representan de la misma manera.

Por una parte, se es un pronombre personal átono perteneciente a la serie $m e$, te, $s e$, nos, os, se y como tal puede funcionar como complemento directo o indirecto. 
Las diferentes características sintáctico-funcionales de se como pronombre se analizan en el apartado 2.1.

Por otra parte, puede aparecer en oraciones cuya principal característica es la de representar procesos y estados como ocurre en las oraciones pasivas, impersonales y medias, las cuales se analizan en el apartado 2.2.

En el presente trabajo adoptamos el análisis contrastivo como punto de partida para la descripción de las diferentes formas de se y sus equivalentes en polaco. El análisis contrastivo supone una herramienta recuperada en los últimos años para analizar las causas de ciertos errores que aparecen durante el aprendizaje de lenguas extranjeras, y que se complementa con las descripciones existentes de la interlengua ${ }^{1}$.

En Campos Fernández de Pierola (2006) y González Cremona \& Palka (2004) se describió la aparición de errores vinculados con los usos de se por influencia del polaco, pero sin profundizar en las causas. En las siguientes páginas describimos en detalle los motivos de la aparición de dichos errores.

\section{DESCRIPCIÓN MORFOSINTÁCTICA}

\subsection{FORMA}

El pronombre español se está marcado en número y persona en la serie $m e, t e, s e$, nos, os, se. En cambio, en polaco no presenta número, persona ni género, aunque sí varía en la flexión causal, careciendo de forma en los casos nominativo y vocativo.

Tabla 1. Declinación del pronombre polaco się

\begin{tabular}{|l|l|}
\hline Nominativo & - \\
\hline Genitivo & siebie \\
\hline Dativo & sobie \\
\hline Acusativo & się/siebie \\
\hline Instrumental & sobą \\
\hline Locativo & sobie \\
\hline Vocativo & - \\
\hline
\end{tabular}

Por lo tanto, cuando en español tenemos un verbo reflexivo acompañado con un pronombre se en función de complemento directo, este se flexiona según el número y persona mientras que en polaco siempre aparecerá la forma się.

\footnotetext{
${ }^{1}$ Una descripción amplia de la interlengua de los aprendices polacos de español se puede encontrar en Fernández Jódar (2006).
} 
Tabla 2. Verbo reflexivo en español y en polaco

\begin{tabular}{|l|l|}
\hline me visto & ubieram się \\
\hline te vistes & ubierasz się \\
\hline se viste & ubiera się \\
\hline nos vestimos & ubieramy się \\
\hline os vestís & ubierajcie się \\
\hline se visten & ubierają się \\
\hline
\end{tabular}

En cambio, el se que aparece en las oraciones impersonales, pasivas reflejas y medias es invariable, puesto que no es un pronombre sino una marca morfológica que nos señala el tipo de construcción.

\subsection{SE DATIVO ANTE PRONOMBRES DE ACUSATIVO}

En la combinación de pronombres átonos en función de complemento indirecto más complemento directo, no se utilizan los pronombres dativos le/les, sino que estos se transforman en se, lo que deriva en las combinaciones se lo/se la/se los/se las. Por lo tanto, no debemos confundir esta forma de le con los casos de se analizados en este capítulo.

(1) Se ( = le) las he dado.

(2) $\mathrm{Se}(=$ le) lo compré porque me pareció una buena idea.

\section{CARACTERÍSTICAS SINTÁCTICO-FUNCIONALES}

\subsection{SE COMO PRONOMBRE}

En este apartado tratamos los tipos de se correferenciales, es decir, aquellos en los que como pronombre hace referencia o equivale a otro elemento de la oración.

\subsubsection{LAS ORACIONES REFLEXIVAS}

En una oración reflexiva el verbo que aparece en el predicado señala una acción que el sujeto ejerce sobre sí mismo, indicado esto mediante uno de los pronombres reflexivos me, te, se, nos, os, se.

Dichos pronombres pueden funcionar como complementos directos, representados en polaco mediante się:

(3) Todas las mañanas Marcin se viste rápidamente. / Co rano Marcin ubiera się szybko. 
O como complementos indirectos, representados en polaco mediante sobie:

(4) Marta fue a los servicios y se arregló el maquillaje. / Marta poszła do łazienki i poprawita sobie makijaż.

\subsubsection{LAS ORACIONES RECÍPROCAS}

Como en el apartado anterior, en las oraciones recíprocas aparece en el predicado un verbo acompañado con uno de los pronombres de la serie me, te, se, nos, os, $s e$ en función de complemento directo (się en polaco) o indirecto (sobie en polaco). Pero en este caso, la acción la ejercen dos o más individuos, los unos sobre los otros, lo cual significa que el sujeto debe ser plural, ya sea estando formado por dos nombres o más o por un nombre en plural:

(5) Carmen y su marido se quieren mucho. / Carmen i jej mąz bardzo się kochają.

(6) Los futbolistas se critican sin parar. / Piłkarze krytykują się bez przerwy.

\subsubsection{LAS ORACIONES CON VERBOS PRONOMINALES}

Los verbos pronominales aparecen acompañados por un pronombre, como su propio nombre indica. Pero dicho pronombre no desempeña ninguna función, no es ni complemento directo ni indirecto, sino un apéndice inseparable del verbo, el cual no puede aparecer sin pronombre. Así ocurre, por ejemplo, con los verbos arrepentirse, atenerse, fugarse, suicidarse, etc. En polaco tenemos podobać się (gustar), gniewać się (enfadarse), bać się (temer), etc. Algunos verbos polacos no utilizan el pronombre się sino el dativo sobie, como ocurre por ejemplo con wyobrażać sobie (imaginarse).

Existen diferentes tipos de verbos pronominales en español:

a. Verbos que no se conjugan sin uno de los pronombres de la serie me, te, se, nos, os, se, como los citados anteriormente.

b. Verbos con dos formas, ya aparezcan con o sin pronombre. El uso u omisión de este cambia el significado del verbo de manera mínima (ir/irse) o totalmente (empeñar/empeñarse). En los casos en los que el significado cambia de forma mínima, el pronombre se, denominado incoativo, suele indicar el inicio de la acción, como ir/irse, dormir/dormirse.

c. Verbos que se conjugan en tercera persona y rigen un complemento indirecto representado mediante los pronombres le/les, como gustar, encantar o parecer. 


\subsubsection{DATIVO ASPECTUAL}

Los verbos relacionados con la ingesta de alimentos o consumo y lectura tienen la particularidad de que pueden utilizarse con el llamado dativo aspectual, pronombres de la serie $m e, t e, s e, n o s, o s$, se. Denota una acción perfectiva, lo que lo pone en relación con el aspecto y la aspectualidad ${ }^{2}$. Obsérvese el ejemplo:

(7) (Se) ha tomado el desayuno.

La distinción aspectual es clave para comprobar cómo la distinción, por un lado, del aspecto morfológico en polaco y, por otro, del dativo aspectual español, y el uso u omisión de los artículos en español puede servir para expresar contenidos comunes como la realización completa o incompleta de un acto. Recordemos que, según Nowikow (2008, p. 396), cuando planteamos una oposición aspectual entre polaco y español, "tenemos que ver con categorías o clases similares pero no idénticas". Asimismo, dicho autor distingue entre los términos aspectivo y aspectual, "refiriéndose el primero al aspecto morfológico y el segundo al concepto de aspectualidad" (Nowikow, 2012c, p. 191). De esta manera, la aspectualidad es "un concepto más amplio que se refiere a diferentes maneras de desarrollar la acción y que admite diversos recursos de expresión" (Nowikow, 2012b, p. 630).

Observemos los siguientes ejemplos:

(8) Stuchaj, zjadteś już zupę? (aspecto perfectivo) / Oye, ¿te has tomado ya la sopa?

(9) Stuchaj, jadteś zupę? (aspecto imperfectivo) / Oye, ¿has tomado Ø sopa?

En las oraciones en polaco el verbo diferencia entre aspecto, como en el ejemplo (8), donde existe conclusión procesal, y aspecto imperfectivo en el ejemplo (9), donde no se da la realización completa del acto. Como observamos, en español la aspectualidad se refleja mediante el uso del artículo definido y el dativo de interés, lo que nos indica conclusión procesal. En cambio, en (9) no existe una lectura conclusiva, puesto que no hay un referente concreto en la realidad extralingüística, sino que se alude a la propia esencia del significado de la entidad sopa, lo que se refuerza mediante la omisión del dativo aspectual.

\subsection{SE COMO MARCA VERBAL}

En el siguiente apartado se analiza el se como marca verbal de la diátesis, es decir, el número de argumentos verbales necesarios en determinadas estructuras, en este caso referentes a la voz pasiva y media y a las oraciones impersonales.

\footnotetext{
${ }^{2}$ Para una descripción detallada del aspecto y la aspectualidad contrastada entre español y polaco, véase Nowikow (2003, 2008, 2010, 2012a, 2012b, 2012c).
} 


\subsubsection{LAS ORACIONES IMPERSONALES CON SE}

Existen diferentes estructuras para expresar en español la impersonalidad. Por una parte, contamos con verbos que describen acciones de fenómenos naturales como llover o nevar, y verbos impersonales gramaticalizados como haber. Por otro lado, los verbos transitivos pueden aparecer teóricamente en diferentes estructuras impersonales (De Molina Redondo, 1974, p. 13) como:

a. Verbo en tercera persona plural:

(10) Dicen que la situación no pinta bien.

(11) En Grecia han decidido no escuchar a Angela Merkel.

b. Verbo en segunda persona del singular:

(12) Nunca sabes qué decirle para que no se enfade.

(13) Hagas lo que hagas, nunca estará contento.

c. Verbo en primera persona del plural:

(14) Como hemos demostrado, no hay una tesis clara.

(15) Hemos avanzado tanto como después hemos retrocedido.

Ciertamente, en los dos últimos casos puede ser que no se trate de oraciones impersonales y que nos refiramos a sujetos auténticos. Es el contexto el que nos ayuda a entender estas oraciones en un sentido $u$ otro.

No obstante, una estructura que tiene un lugar destacado en español por su frecuencia de uso es el de las oraciones impersonales con se, las cuales se caracterizan por la ausencia de sujeto que concuerde con el verbo en número y persona. El verbo siempre aparece en tercera persona del singular y precedido de se, el cual se interpreta como morfema del verbo o marca verbal que denota impersonalidad y ocupa el lugar que correspondería al sujeto.

Las oraciones impersonales con se pueden ser intransitivas:

(16) En Polonia se trabaja mucho.

(17) Se vive a trancas y barrancas en la España actual.

(18) Se canta y baila por las calles.

O transitivas cuando tienen un complemento directo. Estas pueden ser de diferentes tipos según el complemento directo:

a. Verbo transitivo + complemento directo inanimado:

(19) Se vende pocos coches.

(20) Se compra cobre. 
b. Verbo transitivo + complemento directo animado:

(21) Se ayudó a las víctimas de la inundación.

(22) Se busca un agente comercial.

La preposición $a$ del ejemplo nos indica que nos encontramos ante un complemento directo animado y determinado, por lo que no sería correcto que el verbo concordara en plural con este. La omisión de la preposición implicaría que el verbo tuviera que aparecer en plural y que la oración se entendiera como reflexiva o recíproca, pero nunca como impersonal.

c. Verbo transitivo + oración subordinada:

(23) Se cree que fue un ajuste de cuentas.

(24) Se supone que no llegarán a las manos.

Cuando nos encontramos ante una oración subordinada en forma de infinitivo, suelen aparecer dudas respecto a la concordancia del verbo y la forma de entenderse sintácticamente. Por ejemplo, en los verbos de percepción debe tenerse en cuenta si este tiene un sujeto explícito (De Molina Redondo, 1974, p. 15), en cuyo caso se podría entender como pasiva refleja (véase el apartado 2.2.2):

(25) Se ve arder un árbol.

(26) Se ven arder unos árboles.

O si este es un complemento respecto al infinitivo, en cuyo caso no podría entenderse como pasiva refleja:

(27) Se ve talar unos árboles.

(28) *Se ven talar unos árboles.

d. Verbo transitivo en uso absoluto:

(29) Se escribe para matar el tiempo.

(30) Se lee mucho en Polonia.

En los casos en los que disponemos de un verbo transitivo, la marca de impersonalidad se puede aparecer combinada con un pronombre personal:

(31) Han pedido que no se lo (/le) moleste.

En estos casos, aunque tenemos un complemento directo, en la oración impersonal se suele optar preferentemente por el uso de los pronombres le/les, los cuales también están aceptados por la NGLE (2009) en su uso como complementos directos en caso de referirse a personas. En cambio, cuando el complemento directo se refiere a cosa, el uso natural es el de los pronombres lo/los. 
La oración impersonal en polaco resulta equivalente de la española, excepto por la posición de la marca verbal. Mientras en español siempre aparece en posición preverbal, en polaco es arrastrada por la posición de otros elementos de la oración. Compárese:

(32) En Polonia se trabaja mucho. / W Polsce dużo się pracuje.

(33) Se vende pocos coches. / Sprzedaje się mato samochodów.

Por otra parte, el uso de la oración impersonal con se es relativamente menos frecuente en polaco, puesto que se suele optar por otras formas, ya sea mediante el uso de infinitivos o explicitando un sujeto:

(34) Han pedido que no se le moleste. / Poprosili, żeby mu nie przeszkadzać.

(35) Los jugadores del Real Madrid no saben perder. No se les ve nunca contentos. / Pitkarze Realu Madryt nie umieja przegrywać. Nigdy nie widać, żeby byli zadowoleni ${ }^{3}$.

Cabe añadir que las oraciones impersonales, tanto en español como en polaco, pueden ser al mismo tiempo pasivas. Esto solo ocurre en español cuando el tiempo verbal es el presente o pretérito perfecto compuesto:

(36) Cuando se es humillado, no cabe el perdón. / Kiedy zostanie się poniżonym, nie ma miejsca na przebaczenie.

\subsubsection{LAS ORACIONES PASIVAS CON SE (PASIVA REFLEJA)}

Como bien sabemos, tanto en español como en polaco, en las llamadas oraciones pasivas el sujeto, ya sea persona o cosa, sufre la acción o proceso señalado por un verbo transitivo y llevado a cabo por la persona representada en el complemento agente, la cual sería sujeto en una oración activa, tal y como se observa en los siguientes ejemplos:

(37) El libro fue reseñado por un experto. / Ksiażka zostata zrecenzowana przez eksperta.

(38) El experto reseñó el libro. / Ekspert zrecenzowat tę książę.

Recordemos que en polaco la pasiva se construye con los verbos auxiliares być, equivalente a ser y estar en español, y zostać, equivalente a ser y quedar en español. Zostać, por otra parte, solo se utiliza con la forma perfectiva de los verbos y se conjuga en pretérito o futuro.

\footnotetext{
${ }^{3}$ Suelo tomar en consideración las siempre oportunas observaciones del profesor W. Nowikow. Aun así, y sin que sirva de precedente, en este caso he decidido mantener el ejemplo con el Real Madrid y no cambiarlo por el F.C. Barcelona, tal y como sugirió en comunicación personal ( 9 de mayo de 2015).
} 
En polaco se opta por la presencia del participio adverbial pasivo y se omite el uso de verbos auxiliares

(39) Zrecenzowano tę książkę.

(40) Nie pozwolono na wejście dzieci.

Existe en español una forma más de expresar la oración pasiva, la denominada oración pasiva con se o pasiva refleja, la cual no se da en polaco:

(41) Se reseñó el libro.

La pasiva refleja tiene las siguientes características:

- El verbo, en tercera persona, no está formado por el verbo ser más un participio, sino por un verbo en forma activa (reseñó).

- El sujeto no suele preceder al verbo sino que aparece en posición posverbal. Esto se debe a que el sujeto de la pasiva refleja no es información conocida por el oyente. En estos casos, además de la posición posverbal, el sujeto suele tener un determinante definido o numeral. Asimismo, esto motiva que de los siguientes ejemplos el último (45) sea el menos natural:

(42) Se reseñó el libro.

(43) El libro se reseñó.

(44) Se reseñó un libro.

(45) ??Un libro se reseñó.

- El complemento agente suele quedar omitido. Su aparición no es agramatical pero sí poco natural.

- El se que precede al verbo es una marca o morfema de pasividad que sustituye a la forma perifrástica del verbo ser más un participio.

El mayor problema a la hora de analizar las oraciones con se es que en ocasiones se pueden considerar tanto impersonales como pasivas reflejas cuando se trata de verbos transitivos. En el ejemplo siguiente, tomado de Sánchez, Penadés Martínez \& Ruiz Martínez (2008b), la entrada puede entenderse como sujeto o como complemento directo, ya se analice como pasiva con se o como impersonal con se, respectivamente:

(46) Pasiva con se: $\quad$ No se permite la entrada (sujeto) a los niños.

(47) Impersonal con se: No se permite la entrada (complemento directo) a los niños.

Aun así, cabe recordar que hay ciertas características que nos permitirían distinguir entre ambos tipos de oraciones:

- Si el verbo está en singular y el grupo nominal aparecen en singular o plural, pero este último va precedido de la preposición $a$, se entiende la oración como 
impersonal, como se ejemplifica en Sánchez, Penadés Martínez \& Ruiz Martínez (2008):

(48) No se conoce a ninguna persona (complemento directo) que lo haya conseguido.

(49) Poco a poco se va conociendo a los demás (complemento directo).

- Si el verbo está en plural, se entiende la oración como pasiva refleja, puesto que en las oraciones impersonales el verbo solo puede estar en singular. Así, el grupo nominal que funcione como sujeto deberá también estar en plural, ya que debe concordar con el verbo:

(50) No se permiten las bebidas alcohólicas en la Universidad.

- Las oraciones con verbos intransitivos o copulativos se interpretan como impersonales:

(51) Se es lo que se quiere o no se es nada.

De esta manera, se entiende que las oraciones impersonales y la pasiva refleja son equivalentes semánticamente, pero no sintácticamente, puesto que en las impersonales el sujeto léxico sintáctico es cero (Gómez Torrego, 1994, p. 18).

En general, en el español de América, en estos casos en los que una misma oración podría ser interpretada como impersonal o como pasiva refleja, se opta por la impersonalidad con complemento directo. En cambio, en el español peninsular se suele optar por la pasiva refleja. De hecho, según la RAE, la norma culta se inclina por el uso de la pasiva refleja y desaconseja el uso de la impersonal con se (NGLE, 2009).

Como se puede deducir, al no existir la pasiva refleja en polaco, este tipo de oraciones españolas se suelen considerar equivalentes a las impersonales polacas. Es esta confusión la que suele provocar producciones por parte de los aprendices polacos de español de oraciones impersonales con complemento directo que en español son poco naturales, como los ejemplos citados en Campos Fernández de Pierola (2006):

(52) ??Esto se lo hace así.

(53) ?? Aquí el español se lo estudia mal.

Aunque dichos ejemplos podrían considerarse correctos desde un punto de vista gramatical, no resultan nada naturales porque en español peninsular siempre se tenderá a interpretar este tipo de oraciones como pasivas reflejas, por lo que el uso del pronombre de complemento directo resultaría percibido como erróneo.

Evidentemente, siempre serán incorrectos casos en los que el verbo apareciera en plural -lo que denotaría que tratamos con una pasiva refleja- y fuera acompañado 
de un pronombre de complemento directo que debería ser sujeto, lo cual resulta a todas luces agramatical en español:

(54) *Aquí las lenguas se las estudian mal.

\subsubsection{LAS ORACIONES MEDIAS CON $S E$}

En estas oraciones el se es una marca que señala la voz media, así como ocurre con el se de las pasivas reflejas y de las impersonales. En polaco tenemos się.

Pero existen otras diferencias respecto a los dos tipos anteriores de oraciones:

- Siempre tenemos un sujeto que se refiere a la persona o cosa que sufre la acción o efecto expresado mediante el verbo.

(55) La mantequilla se derrite fácilmente. / Masło tatwo się topi.

- En la voz media el sujeto participa de la acción involuntariamente sufriendo la modificación expresada con el verbo:

(56) La taza de porcelana se hizo añicos. / Porcelanowa filiżanka rozbiła się na kawatki.

(57) El hombre se quemó al coger la taza. / Mężczyzna poparzyt się biorąc filiżankę.

- No existe un agente causante de la acción o proceso presentado por el verbo, como se observa en los ejemplos anteriores.

- En polaco, como observamos en los ejemplos, la marca verbal sie puede tener posición pre- o posverbal dependiendo del resto de elementos oracionales.

\section{CONCLUSIONES}

Como hemos observado, existe una gran variedad de valores asociados al se español y al się polaco. Aun así, en ambas lenguas se pueden agrupar en torno a dos valores: pronombres y marcas verbales.

De esta manera, por una parte nos encontramos con una serie de pronombres que varían según el número y persona en español y que equivalen a dos únicas formas en polaco según la función gramatical.

Por otra parte, nos topamos con una estructura inexistente en polaco como es la pasiva refleja, la cual suele ser representada en polaco mediante las oraciones impersonales. Que no tenga equivalente motiva ciertas dificultades para los aprendices polacos de español. Además, este tipo de oraciones suele ser obviado durante el aprendizaje, por lo que las dificultades permanecen a lo largo del tiempo y tienden a fosilizarse. Por lo tanto, era necesario aportar una descripción detallada y contrastiva de las diferentes estructuras en polaco y español para que fueran de fácil reconocimiento por parte de los hablantes polacos de español como lengua extranjera. 


\section{BIBLIOGRAFÍA}

Alarcos Llorach, E. (1984). Valores de se. En: Estudios de gramática funcional (pp. 213-222). Madrid: Gredos.

Alcina, J. \& Blecua, J. M. (1982 [1975]). Gramática española. Barcelona: Ariel.

Barra Jover, M. (1996). Dativo de interés, dativo aspectual y las marcas de aspecto perfectivo en español. Verba. Anuario galego de filoloxia, 23, 121-146.

Bąk, P. (1987). Gramatyka języka polskiego. Zarys popularny. Warsovia: Wiedza Powszechna.

Blaylock, C. (1986). El se impersonal en el español de América. En: Actas del Primer Congreso Internacional sobre el español de América (pp. 91-111). Ciudad de México: FCEC.

Bobes, Ma del C. (1974). Construcciones castellanas con SE. Revista Española de Lingüística, 4 (2), 301-325.

Campos Fernández de Pierola, P. (2006). Español para hablantes de polaco. Madrid: SGEL.

De Molina Redondo, J. A. (1974). Usos de se. Cuestiones sintácticas y léxicas. Madrid: SGEL.

Fernández Jódar, R. (2006). Análisis de errores léxicos, morfosintácticos y gráficos en la lengua escrita de los aprendices polacos de español (Tesis doctoral). Poznań: Uniwersytet im. Adama Mickiewicza. Disponible en http://www.mec.es/redele/Biblioteca2007/RaulFernandez.shtml

Gili Gaya, S. (1990). Curso superior de sintaxis española. Barcelona: Biblograf.

Gómez Torrego, L. (1994 [1992]). La impersonalidad gramatical: descripción y norma. Madrid: Arco Libros.

González Cremona, P. \& Palka, E. (2004). Guía de pecadores o Compendio de diversos errores léxicos, estilísticos y sintácticos, de los que deben desprenderse aquellas almas que quieran perseverar en el camino de la perfección lingüistica. Kraków: Księgarnia Akademicka.

Jaworski, M. (1987). Podręczna gramatyka języka polskiego. Warszawa: Wydawnictwo Szkolne i Pedagogiczne.

Martí Sánchez, M., Penadés Martínez, I. \& Ruiz Martínez, A. Mª (2008a). Gramática española por niveles (vol. 1). Madrid: Edinumen.

- (2008b). Gramática española por niveles (vol. 2). Madrid: Edinumen.

Nagórko, A. (2005). Zarys gramatyki polskiej. Warszawa: Wydawnictwo Naukowe PWN.

- (2010). Podręczna gramatyka języka polskiego. Warszawa: Wydawnictwo Naukowe PWN.

NGLE = Real Academia Española y Asociación de Academias de la Lengua Española (2009). Nueva gramática de la lengua española. Madrid: Espasa-Libros.

Nowikow, W. (2003). Acerca de las relaciones entre aspecto y el modo accional desde una perspectiva tipológico-comparada. Language Design. Journal of Theoretical and experimental Linguistics, 5, 51-66.

- (2008). Sobre el contenido funcional del aspecto en relación con las categorías verbales del español y del polaco. En: A. Veiga \& $\mathrm{M}^{\mathrm{a}}$ I. González Rey (Eds.), La diversité linguistique (pp. 395-399). Lugo: Editorial Axac.

- (2010). En torno a la interferencia en la enseñanza de los pretéritos a los alumnos polacos: tiempo vs. Aspecto. En: G. Luquet \& W. Nowikow (Eds.), La recherche en langues romanes. Théories et applications (pp. 289-302). Łódź: Lodz Academy of International Studies.

- (2012a). Lenguas 'artículo + tiempo' vs. Lenguas 'caso + aspecto' (sobre las diferencias tipológicas entre el español y el polaco). En: A. Dutka-Mankowska, A. Kieliszczyk \& E. Pilecka (Eds.), Grammaticis unitis (pp. 237-244). Warszawa: Wydawnictwa Uniwersytetu Warszawskiego.

- (2012b). Sobre dos dimensiones de la oposición pretérito / copretérito. En: T. Jiménez Juliá, B. López Meirana, V. Vázquez Rozas \& A. Veiga Rodríguez (Eds.), Cum corde et in nova 
grammatica. Estudios ofrecidos a Guillermo Rojo (pp. 625-631). Santiago de Compostela: Universidad de Santiago de Compostela.

- (2012c). Sobre el valor gramatical de los tiempos canté y cantaba y su empleo en contextos de [ \pm delimitación temporal]. Neophilologia, 24, 185-192.

Presa Gónzalez, F. (2008). Gramática polaca. Madrid: Cátedra. 
